\title{
Prolactin secretion patterns: basic mechanisms and clinical implications for reproduction
}

\author{
Marcel Egli, Brigitte Leeners ${ }^{1}$ and Tillmann H C Kruger $^{2}$ \\ Space Biology Group, Swiss Federal Institute of Technology Zurich, ETH Zurich, 8005 Zurich, Switzerland, ${ }^{1}$ Clinics \\ for Reproductive Endocrinology, Department of Gynecology and Obstetrics, University Hospital Zurich, 8091 Zurich, \\ Switzerland and ${ }^{2}$ Laboratory for Sexual Medicine, Department of Psychiatry, Social Psychiatry and Psychotherapy, \\ Medical School Hannover, Carl-Neuberg-Strasse 1, 30625 Hannover, Germany
}

Correspondence should be addressed to T H C Kruger; Email: krueger.tillmann@mh-hannover.de

M Egli and B Leeners contributed equally to this work

\begin{abstract}
Prolactin (PRL) is one of the most versatile hormones in the mammalian body affecting reproductive, sexual, metabolic, immune, and other functions. It is therefore not surprising that the neural control of PRL secretion is complex, involving the coordinated actions of several hypothalamic nuclei. A plethora of experimental data exists on the hypothalamic control of hormone secretion under various physiological stimuli. There have been even mathematical models and computer studies published, which help to understand the complex hypothalamic-pituitary network. Nevertheless, the putative role of PRL for human reproduction still has to be clarified. Here, we review data on the underlying mechanisms controlling PRL secretion using both experimental and mathematical approaches. These investigations primarily focus on rhythmic secretion in rats during early pregnancy or pseudopregnancy, and they point to the important role of oxytocin as a crucial PRL-releasing factor. Recent data on human studies and their theoretical and clinical implications are reviewed as well. In particular, studies demonstrating a sustained PRL surge after sexual climax in males and females are presented, indicating possible implications for both sexual satiation and reproductive functions. Taking these data together, there is evidence for the hypothesis that the PRL surge induced by sexual activity, together with the altered PRL rhythmic pattern, is important for successful initialization of pregnancy not only in rodents but also possibly in humans. However, further investigations are needed to clarify such a role in humans.
\end{abstract}

Reproduction (2010) $\mathbf{1 4 0} 643-654$

\section{Introduction}

Prolactin (PRL) is an exceptional hormone with important implications for reproduction and sexual behavior (Ben-Jonathan et al. 2008). More than 300 biological functions, for example immune functions, osmoregulation, reproduction, and behavior, have been described so far, and its pleiotropic features are unique (Freeman et al. 2000, Grattan \& Kokay 2008).

PRL secretion from lactotrophs of the anterior lobe of the pituitary gland is controlled by stimulatory as well as inhibitory factors. Ambient lighting conditions entrain PRL surges to the particular time (Bethea \& Neill 1979, 1980) of day possibly via actions of the suprachiasmatic nucleus (SCN) that is regarded as the master clock in mammals (Reppert \& Weaver 2002). We investigated the underlying mechanisms that control PRL secretion by using a joint biological/mathematical approach. Mathematical modeling and computer studies represent an innovative approach to understand the complex hypothalamo-pituitary network (Leng \& Macgregor 2008).
In addition, we aimed to elucidate the role of PRL in human sexual behavior and reproduction. Until recently, human studies were rare, mainly focusing on states of chronic hyperprolactinemia and the implications for sexual and reproductive function. Therefore, we have systematically investigated the role of serum PRL in human male and female sexual behavior and have developed theoretical models on the potential physiological significance of PRL in humans.

Accordingly, this review aims to highlight some important physiological features of PRL secretion patterns. Moreover, we summarize essential findings on altered PRL secretion patterns in animals and humans, discuss the implications for reproductive functions, and disclose promising future investigations.

\section{Secretory rhythms of pituitary hormones}

Hormone secretion in mammals is precisely balanced to the needs of the organism in its current state. The final concentration of several circulating pituitary 
hormones is defined by releasing and/or inhibiting factors originating from hypothalamic nuclei mainly. These nuclei in turn are controlled by hierarchically higher brain sites, which have an integrative function. The afferent inputs to these integrative sites may be of neural or hormonal origin. Furthermore, neural networks controlling hormone secretion often include feedback loops in which the secreted signaling molecule modifies its own secretion pattern either directly or indirectly.

Some endocrine systems exhibit secretion patterns with a period of $24 \mathrm{~h}$. These circadian rhythms oscillate usually in relation to the ambient light/dark cycle and are in synchronization with physiological rhythms like the sleep/wake cycle or the daily fluctuation of the body temperature. Studies have shown that mammalian organisms possess a central pacemaker in the brain which functions like a body clock (Schibler \& SassoneCorsi 2002). This pacemaker is represented in the SCN and governs peripheral oscillators, which are responsible for physiological output rhythms (Reppert \& Weaver 2002). Further features of the central pacemaker are the generation of an endogenous activity rhythm under temporal isolation and the entrainment of this rhythm to external time cues like the ambient light/dark cycle (Reppert \& Weaver 2002).

It is reasonable to assume that the central rhythm generator is involved in the generation of circadian secretory rhythms. Indeed, lesion studies demonstrated that after ablation of the central pacemaker, most of the secretory rhythms vanish (Refinetti et al. 1994, Warren et al. 1994, Weaver 1998). Thus, besides the highly complicated mechanism through the action of releasing/ inhibiting factors that control the amount of hormones which is secreted, there appears to be an additional system assuring appropriate timing of hormone surges.

One aspect of our research has been dedicated to the mechanisms responsible for entrainment, generation, and expression of secretory rhythms of the pituitary hormone PRL. The secretory profile of PRL is well established in female rats, showing three distinct secretory patterns that are related to particular physiological stages (Fig. 1). As extensively demonstrated by scientific experiments, the level of circulating PRL remains low in normal cycling rats throughout most of the estrous cycle. There is just one prominent PRL surge at proestrus, which is coincidental with $\mathrm{LH}$ during the cycle that has a period of 4-5 days (Fig. 1A; Freeman et al. 2000). A second type of PRL secretory pattern involves pups suckling on the mother animal. In this situation, PRL secretion is induced via a neuroendocrine reflex arc (Fig. 1B). As soon as pups start to suckle, PRL secretion increases and, depending on how many pups are suckling, higher values of circulating PRL can be measured. A third pattern can be observed for 10 days during pregnancy and 12 days during pseudopregnancy in response to the mating stimulus. This rhythmic pattern consists of an increase in PRL secretion in the early morning $(0100-0300 \mathrm{~h}$, nocturnal surge) and late afternoon (1400-1800 h, diurnal surge) (Freeman \& Neill 1972, Freeman et al. 1974, Smith et al. 1975; Fig. 1C).

During the past few years, we have been investigating potential mechanisms involved in controlling PRL secretion in rats. This includes the design of mathematical models based on experimental data
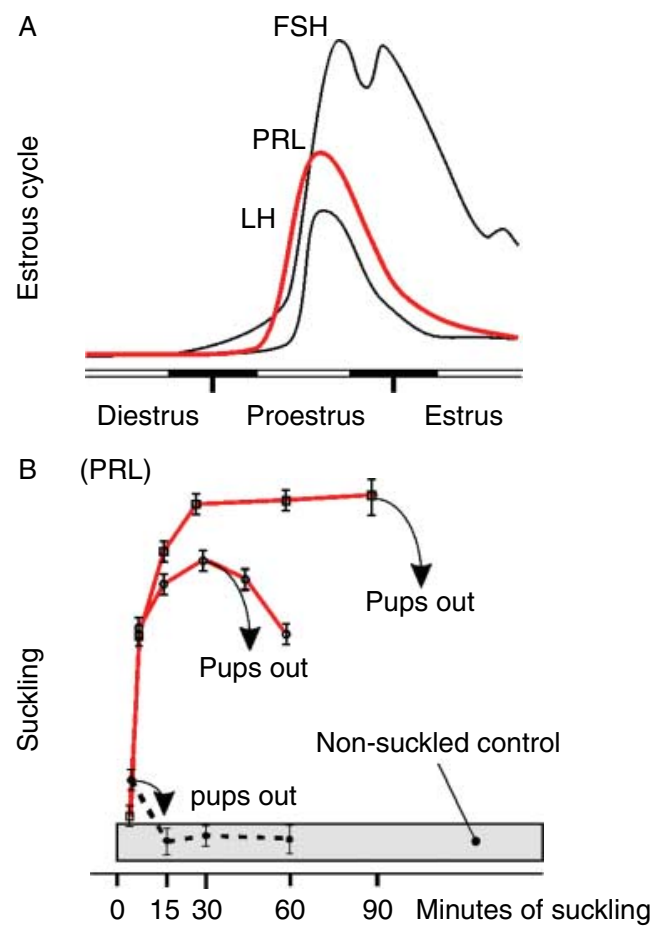

C (PRL)

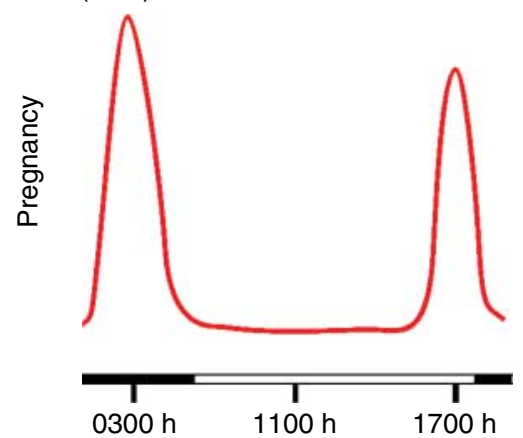

Figure 1 Different PRL secretory patterns of female rats. (A) Schematic representation of the $\mathrm{LH}, \mathrm{FSH}$, and PRL levels during the estrous cycle in normal animals (Erskine 1995). (B) Schematic representation of the $\mathrm{PRL}$ response of a nursing rat to the suckling stimulus of one, four, and six pups respectively. The PRL magnitude correlates with the number of suckling pups and the duration of suckling. Adapted, with permission, from Grosvenor CE, Shyr SW, Goodman GT \& Mena F 1986

Comparison of plasma profiles of oxytocin and prolactin following suckling in the rat. Neuroendocrinology 43 679-685. (C) 1986 S. Karger AG, Basel. (C) Schematic representation of the mating-induced PRL secretion pattern. The surges occur autonomously every day at around 0300 and $1700 \mathrm{~h}$ for 10-14 days (Egli et al. 2004). For a comparable figure on multiple modes of prolactin secretion, see also Grattan \& Kokay (2008). 
collected in parallel. The results gathered led to the identification of a neural network that allows the simulation of several secretory rhythms of PRL known in rats (Egli et al. 2004, 2006, Bertram et al. 2006). Computer simulations illustrate the interplay between releasing and inhibiting factors to generate PRL secretory patterns in normal cycling as well as pregnant/ pseudopregnant rats.

\section{Proposed neural network in charge of PRL secretion}

Secretion from lactotrophs is controlled by stimulatory and inhibitory inputs supplied by neurosecretory cells in the hypothalamus via the portal vessel system (Arey et al. 1989, Lamberts \& Macleod 1990, Freeman et al. 2000). The PRL-inhibiting factor is dopamine (DA), and this plays the most prominent role in PRL secretion (Lamberts \& Macleod 1990, Ben-Jonathan \& Hnasko 2001). It is released by three hypothalamic neural populations: i) periventricular hypothalamic dopaminergic neurons, ii) tuberohypophyseal neurons, and iii) tuberoinfundibular neurons of the arcuate nucleus (Freeman et al. 2000). One PRL-releasing factor candidate is oxytocin. One daily stimulatory rhythm regulating PRL secretion is unveiled in ovariectomized (OVX) rats in which the DA receptor is blocked at varying times throughout the day (Arey et al. 1989). It was possible to block this rhythm with an oxytocin antagonist, suggesting that oxytocin stimulates PRL secretion (Arey \& Freeman 1989, 1992). Furthermore, a prominent oxytocin surge during the afternoon can be measured in the serum of cervically stimulated rats (inducing pseudopregnancy). This surge is coincident with the diurnal PRL surge (Egli et al. 2004, Bertram et al. 2006). All these experimental results together indicate that oxytocin is a physiological releasing factor of PRL.

Both DA and oxytocin neurons seem to be influenced by neurons in the SCN. Vasoactive intestinal peptide (VIP) fibers originating in the SCN innervate DA neurons in the arcuate nucleus (Gerhold et al. 2001), and more recent data suggest that VIP fibers also innervate oxytocin neurons in the periventricular nucleus (PVN; Egli et al. 2004).

\section{Mathematical modeling of PRL secretion patterns in rats}

In order to analyze the core principles of the PRL secretion controlling system and to illustrate the dynamic interactions, mathematical modeling was applied. Because modeling requires a reduction of the actual system to core functions, the most important network parameters were selected (Fig. 2). Thereafter, equations were designed which describe the behavior of the selected parameters in the neural network.

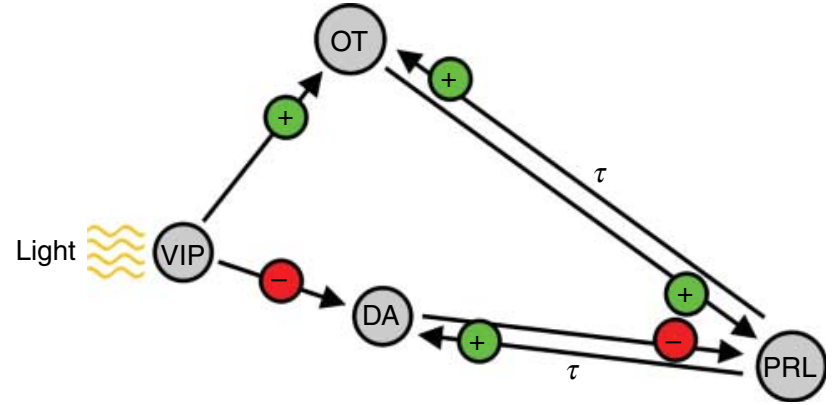

Figure 2 Sketch of the proposed neural network used for mathematical modeling of PRL secretion patterns. DA, population of dopaminergic neurons of arcuate nucleus; OT, population of oxytocinergic neurons of the periventricular nucleus; PRL, lactotrophs of the anterior lobe of the pituitary gland; VIP, population of SCN neurons transmitting timing signals via vasoactive intestinal peptide. The symbols + and indicate the characteristics of the input (stimulatory or inhibitory). $\tau$ denotes the time delay.

All equations together form a phenomenological model of PRL secretion.

The modeling process was started by describing the interaction between the hypothalamic DA neurons and pituitary lactotrophs only. As previously mentioned, DA predominantly inhibits PRL secretion. PRL in turn feeds back time delayed on the DA neurons stimulating DA synthesis and secretion (Gudelsky \& Porter 1980, DeMaria et al. 1999, Lerant et al. 2001). Thus, PRL causes activation of DA neurons, which suppress their own PRL secretion (Bertram et al. 2006). This kind of feedback loop produces autonomous oscillation of the partners after initial perturbance. This means that the underlying mechanism responsible for PRL oscillation in early pregnant or pseudopregnant rats could be based on the described feedback loop between hypothalamic DA neurons and pituitary lactotrophs (Bertram et al. 2006).

Additional parameters, such as oxytocin, which is an important player in PRL secretion (Egli et al. 2004), have been included in the mathematical model in the second step. Up to now, only controversial data are available regarding the $\mathrm{PRL}$ effect on oxytocin containing periventricular neurons (Ghosh \& Sladek 1995, Kokay et al. 2006, White \& Samson 2006). The mathematical model is based on the assumption that PRL exerts a stimulatory influence on oxytocin containing PVN cells. However, additional experiments need to be carried out in the future to elucidate the real nature of the PRL influence on oxytocin containing PVN neurons.

Since PRL secretion entrains to the ambient light/dark cycle (Bertram et al. 2006), further parameters were introduced into the mathematical model to allow interaction between the lighting conditions and the timing of the PRL surges.

Figure $3 \mathrm{~A}, \mathrm{C}$, and $\mathrm{E}$ show the simulation of the PRL rhythm of early pregnant/pseudopregnant rats calculated by the mathematical model that comprises three 

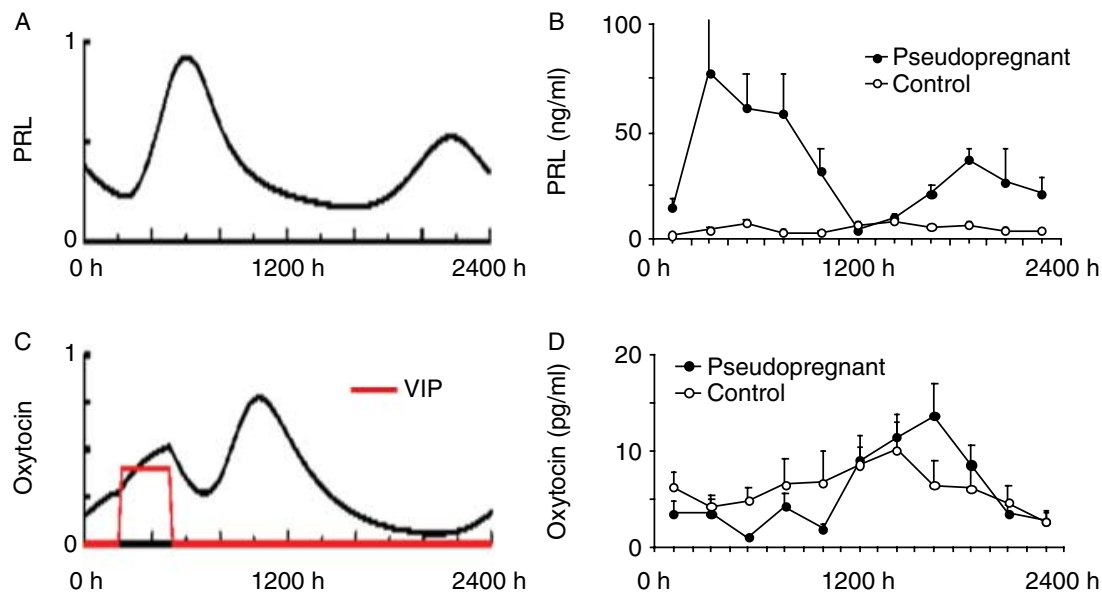

Figure 3 Comparison of the simulation and the experimental data measured in rats. The simulation of PRL secretion (A) is remarkably similar to the measured fluctuation in pseudopregnant animals after cervical stimulation (B, filled circles). In contrast, PRL values of untreated animals

$E$
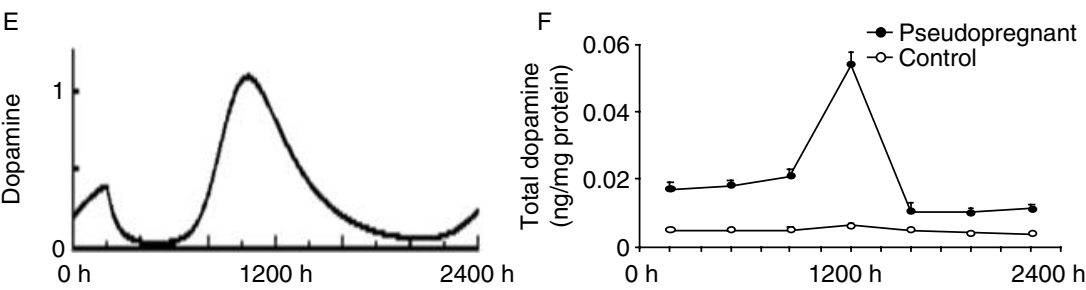
(not stimulated) do not show fluctuation (B, open circles). Similarly, the calculated (C) and the determined oxytocin release patterns (D) are comparable. However, the calculated oxytocin surge appears shortly before the values peak in rats. The VIP timing signal is included in C (red). Calculated dopamine values (E) match the actual fluctuation measured in pseudopregnant rats (F).

equations (for a detailed description of the model, see Egli et al. (2004)). The actual experimental values measured in the animals are displayed in the second column of Fig. 3B, $\mathrm{D}$, and $\mathrm{F}$. In the model, oxytocin (PRL-releasing factor), which is released in response to the mating stimulus (Egli et al. 2006), serves as a trigger signal to induce a PRL surge. This first PRL surge perturbs the hypothalamopituitary PRL-DA system and switches on the oscillatory PRL secretion as described earlier (Fig. 3A). In addition, VIP in the morning exerts a depressing effect on DA activity. Thus, the elevated VIP value (Fig. 3C, red) reduces DA activity (Fig. 3E). The reduction in DA lowers the inhibitory tone to the lactotrophs, enabling the occurrence of a prominent nocturnal (early morning) PRL surge (Fig. 3A). Therefore, VIP facilitates the occurrence of the nocturnal PRL surge, and at the same time, it is entraining the PRL rhythm to a $24 \mathrm{~h}$ period. Without the periodic VIP release, the morning PRL surge would drift due to the free-running DA-PRL rhythm (with periods $>24 \mathrm{~h}$, data not shown). In addition, the VIP influence causes PRL surges of different magnitude (Fig. 3A). This asymmetry of the PRL surges is typically observed in early pregnant/pseudopregnant rats (Fig. 3B; Smith et al. 1975). The diurnal (late afternoon) PRL surge in this mathematical model is solely driven by oxytocin (Fig. 3C and D). DA oscillation is perfectly out of phase with PRL (Fig. 3A, B, E, and F).

Although the mathematical model presented consists of three equations only, it is capable of reproducing the main characteristics of the PRL secretory rhythm of early pregnant/pseudopregnant rats (Fig. 3B, D and F).
Furthermore, it suggests possible temporal releasing patterns for the PRL stimulatory and inhibitory factors oxytocin and DA, as well as for the timing signal VIP, which are necessary for generating the PRL rhythms (Fig. 3A). To illustrate the additional phases of pregnancy, more sophisticated mathematical models are necessary, similar to the ones we published earlier (Bertram et al. 2006). These models have been developed further and also take into account the termination of the oscillatory PRL secretion pattern that is based on a sustained increase in DA release associated with the onset of placental lactogen secretion (Grattan \& Kokay 2008). The models, however, do not simulate the hyperprolactinemia situation of late pregnancy and lactation, which are most likely due to diminished responsiveness of the tuberoinfundibular DA (TIDA) neurons to PRL feedback (Arbogast \& Voogt 1996). This in turn - at least for lactation - seems to be caused by suckling stimulusinduced suppression of tyrosine hydroxylase, the rate-limiting enzyme in DA biosynthesis, and gene expression in the TIDA neurons of pup-exposed dams. Moreover, there are some differences between rat and human physiology in the sense that chronically elevated PRL occurs in human pregnancy from at least week 10 (Boyar et al. 1975), in contrast to the pulsatile secretion in rats. Possibly, adaptive changes in the network controlling PRL secretion in humans occur earlier than in rats. However, this needs further investigation.

Thus, the mathematical models presented were designed for the PRL secretion in rats and cannot be applied to humans without modifications. As critical 
parameters of the PRL secretion controlling system in humans are missing, this impedes the design of a detailed mathematical model. Nevertheless, the rat still serves as an indispensable source of information on the neuroendocrine regulation of PRL secretion (Ben-Jonathan et al. 2008), and thus the rat model is a very valid guide for a future human model.

\section{PRL secretion patterns in humans and the clinical implications}

PRL is involved in the regulation of several human reproductive functions mainly via the modulating effects of gonadotropins (Kelly et al. 1993). Furthermore, PRL seems to play a critical role in human ovarian function due to the observation that hyperprolactinemia facilitates the development of amenorrhea and modifications of the luteal phase of the menstrual cycle (Kauppila et al. 1988). Levels of circulating PRL between 3 and $15 \mu \mathrm{g} / \mathrm{l}$ are considered necessary for maintaining normal reproductive function, and levels below and above are associated with an increased rate of infertility (Kauppila et al. 1988). Even though hypoprolactinemia does not cause major clinical problems, a minimum concentration between 1 and $3 \mu \mathrm{g} / \mathrm{l}$ is thought to be necessary for the physiological regulation of ovarian function (Schwarzler et al. 1997).

\section{Menstrual cycle}

PRL patterns in women are similar to those elucidated in female rats. There is some evidence that a PRL surge occurs during ovulation coincident with the secretory peak of LH as in rodents (Vekemans et al. 1977, Suganuma et al. 1988), although the extent seems to be much weaker in women than in rats (Ben-Jonathan et al. 2008). Furthermore, in comparison to the normally low circulating levels of PRL (5-25 ng/ml; Kacsoh 2000), elevated levels have been reported in the late follicular phase and during the luteal phase of the normal menstrual cycle (L'Hermite \& Robyn 1972, Brumstead \& Riddick 1992), which might - at least partly - be due to an increase in estradiol. However, currently available data on the effect of estradiol in the regulation of PRL secretion in humans are controversial (Ben-Jonathan et al. 2008). In contrast to rodents, the normal daily PRL secretory profile of humans displays a distinct circadian pattern characterized by a rise during nocturnal sleep and a rapid fall after awakening (Kawagoe et al. 1988). This $24 \mathrm{~h}$ pattern shows the same features throughout the menstrual cycle, but the levels are generally higher during the luteal phase than during the follicular phase (Kawagoe et al. 1988). It is still controversial whether this daily PRL secretory pattern follows the sleep-wakening cycle or the circadian rhythm.

\section{Corpus luteum}

Successful pregnancy involves a series of physiological changes in the conceptus, uterus, and ovaries/corpus luteum in women. Major goal of these changes in early pregnancy is to prevent the functional and structural degradation of the corpus luteum (luteolysis), which would terminate progesterone secretion. Studies have shown that PRL-receptor (PRLR) in preovulatory granulosa cells may be involved in the coordination between granulosa cells and follicular macrophages in the process of ovulation (Vlahos et al. 2001). In humans, the lifespan of the corpus luteum after ovulation is sufficient to allow movement of the early embryo through the oviduct, preparation of the uterus for implantation, and the embryo invasion of the endometrium (Csapo \& Pulkkinen 1978). However, the regression of the corpus luteum in the course of the normal cycle takes place just before the developing placenta produces sufficient progesterone to keep the uterus in a supportive state until the end of gestation (Stouffer \& Hearn 1998). Therefore, it is crucial for the continuation of pregnancy after egg fertilization that maternal recognition occurs to signal the extension of luteal function, at least until the essential activities are replaced by placental functions (luteal-placental shift). During this period, human chorionic gonadotropin (hCG) is one of the major and well-established factors in the recognition of pregnancy. HCG is produced and secreted by the syncytiotrophoblast into the maternal compartment where it plays a key endocrine role (Katabuchi \& Ohba 2008). It also stimulates syncytiotrophoblast formation in an autocrine manner (Handschuh et al. 2007). Its secretion by the trophoblast together with $\mathrm{LH}$ secretion is essential for the secretory maintenance of the corpus luteum. Nevertheless, it is surprising that despite the importance of maternal recognition in the first phase of human pregnancy, very little data exist on the underlying pathophysiology (Stouffer \& Hearn 1998). Although PRL is a luteotrophic hormone in rodents, its role in the regulation of the corpus luteum differs greatly in mammalian species (Niswender et al. 2000). In humans, hypo- as well as hyperprolactinemia may cause luteal function deficiency (Garcea et al. 1983, Hunter 1984, Kauppila et al. 1988, Gu 1993).

Significantly elevated concentrations of PRL are detected in cytosolic extracts of premenopausal ovaries than in postmenopausal ovaries (Schwarzler et al. 1997). Evidence of a direct effect of PRL in steroidogenesis is given by several studies showing the expression of PRLR on human-luteinized granulosa cells (Alila et al. 1987, Schwarzler et al. 1997, Vlahos et al. 2001). McNatty et al. (1974) have even discovered that the effect of PRL on steroidogenesis is dose-dependent, showing doses $<100 \mathrm{ng} / \mathrm{ml}$ as stimulating and doses above $100 \mathrm{ng} / \mathrm{ml}$ as inhibiting progesterone production. 
Therefore, PRL might also be expected to assist in the maintenance of progesterone production (Perks et al. 2003). Interestingly, in vitro studies showed that a high level of PRL increased progesterone only in midcycle cells during the initial $48 \mathrm{~h}$ of culture (Alila et al. 1987). The fact that PRL can be localized by immunostaining in the human corpus luteum but not in the ovarian stroma further supports its role in luteal function (KhanDawood 1988). PRLR transcripts were detected in the extracted RNA of mature follicles, but no detectable staining was noted in secondary and early antral follicles, which suggests that the effects of PRL are exerted around the time of ovulation (Vlahos et al. 2001).

Pharmacological suppression of PRL secretion by a high dose of bromocriptine (DA receptor agonist) causes a moderate reduction in plasma progesterone (Schulz et al. 1978, Richardson et al. 1985). McNatty et al. (1974) demonstrated that a high concentration of PRL in the follicular fluid may depress the progesterone secretion by granulosa cells. Higher concentrations of PRL may reduce $17 \beta$-estradiol production induced by hCG in human luteal cells in vitro (Tan \& Biggs 1983). On the other hand, the production of progesterone and estrogen was higher when hCG was applied in combination with PRL than when hCG only was applied (Hunter 1984). PRL inhibits the catabolism of the corpus luteum and is responsible for maintaining a large number of $\mathrm{LH}$ and estradiol receptors (Leroy-Martin et al. 1989). PRL may also contribute significantly to early corpus luteum formation and survival by acting as a potent antiapoptotic factor for human granulosa cells (Perks et al. 2003). Such a correlation is supported by the observation that there were lower levels of apoptosis in the granulosa cells of women undergoing IVF who conceived (Perks et al. 2003). It is therefore likely that the increased PRL level during pregnancy exerts a regulatory function on the steroidogenesis of human luteal tissue (Hiroi 1988, Gu 1993), which is, in turn, crucial for successful pregnancy.

So far both hyper- and hypoprolactinemia have been investigated in the context of follicular and corpus luteum function, but there is no information available as to whether release patterns of PRL are associated with pathological situations. Differences in the PRL secretion rhythm might disturb conception and early pregnancy, as described for LH in combination with PRL (Soules et al. 1989). For example, women with luteal phase deficiency show different PRL pulse amplitudes in the early follicular phase in comparison to normal women (Soules et al. 1991). These abnormalities are associated with definite alterations in gonadotropin secretion (Soules et al. 1991). The specific binding of $\mathrm{LH}$ in human luteal tissue is reduced in the presence of very high or very low levels of PRL (Garcea et al. 1983). Results from Hinney et al. (1995) support the finding that PRL episodes in combination with LH pulses regulate progesterone and estradiol secretion in the human corpus luteum, i.e. PRL pulses are necessary for the effect of $\mathrm{LH}$ pulses. These results show different secretion patterns during the menstrual cycle, with the highest incidence of coincident $\mathrm{LH}$ and PRL pulses during the mid- and late luteal phases. Studies have shown that some women show a close correlation between increased estradiol secretion, as well as progesterone secretion, and the prior occurrence of $\mathrm{LH}$ and PRL pulses (Hinney et al. 1995). In contrast, other women show fluctuation of both gonadal steroids with no particular correlation to LH surge. This suggests a certain degree of autonomy in the regulation of the corpora lutea (Hinney et al. 1995). Although the clinical implications of these differences have not yet been investigated, it seems likely that they might also be associated with differences in reproductive function.

\section{Sexual behavior and reproduction}

To better understand the physiological role of PRL in reproduction and sexual behavior in humans, we have systematically investigated PRL plasma during the sexual response cycle in females and males. A series of studies showed that orgasm in humans induces pronounced and long-lasting secretion of peripheral PRL with significantly higher levels of PRL in females (Fig. 4; Exton et al. 2001). This effect was not observed during sexual arousal per se (Kruger et al. 1998, 2003a, Exton et al. 1999, 2000). Furthermore, the magnitude of the PRL increase following intercourse was $400 \%$ greater than following masturbation, which may indicate the biological significance of cervicovaginal stimulation and/or physical contact with a partner (Brody \& Kruger 2006). The results lead us to formulate two theories on the function of increased PRL levels after sexual activity (Fig. 5). First, PRL may take part in a sexual satiation mechanism indicating a reduced dopaminergic tone in hypothalamic brain areas after orgasm and/or serving as a negative feedback on dopaminergic neurons in mesolimbocortical, nigrostriatal, and other diencephalic brain areas that are crucial for appetitive behavior and reward (Kruger et al. 2002). Second, in parallel to animal studies, PRL might be a part of an orgasm-induced neuroendocrine reproductive reflex optimizing fertility and conception. Regarding the first hypothesis, we have systematically altered PRL plasma levels in order to investigate the effects on acute sexual drive and function. Since PRL and its antagonists are not available for use in humans, PRL levels were pharmacologically altered using TRH for increasing PRL levels, and DA receptor agonist (cabergoline) for decreasing them (Kruger et al. 2003 b). Although this methodological approach has some limitations, this study provided evidence of close interaction between increased, decreased, or restored PRL levels and sexual drive and function, with the highest values on the acute sexual experience scale (ASES) in the low PRL condition and lowest values on the 

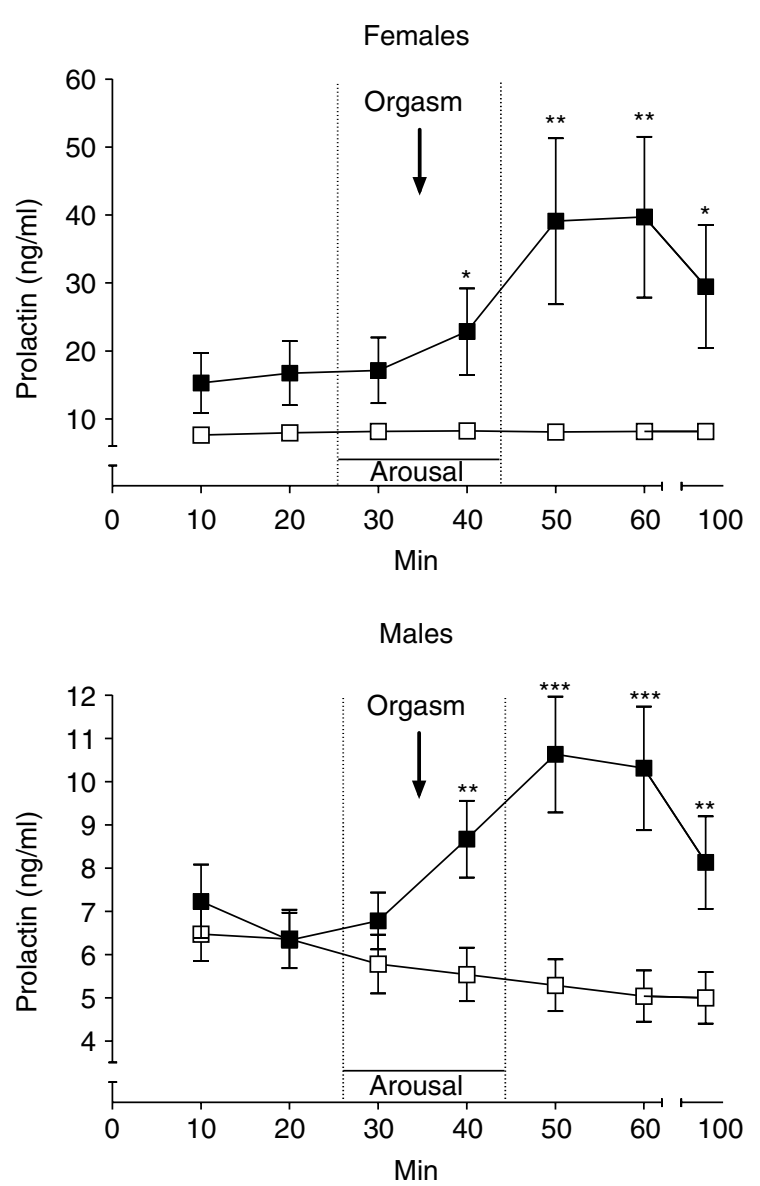

Figure 4 Effect of orgasm on peripheral PRL concentrations in human males and females before, during, and after sexual intercourse (filled squares) and during a control session (open squares). ${ }^{*} P<0.05$; ${ }^{* *} P<0.01 ;{ }^{* * *} P<0.001$. Reproduced, with permission, from Exton MS, Kruger TH, Koch M, Paulson E, Knapp W, Hartmann U \& Schedlowski M 2001 Coitus-induced orgasm stimulates prolactin secretion in healthy subjects. Psychoneuroendocrinology 26 287-294. (c) 2001 Elsevier Science Ltd.

ASES in the high PRL condition. Restored PRL levels were induced by administration of both drugs that led to an adjustment of effects. The inhibitory effects of PRL on sexual appetence in humans are well known from chronic hyperprolactinemia, which can be observed physiologically during lactation and pregnancy, as a side effect of various pharmacological treatments and in causes of prolactinoma. Pharmacological treatment of chronic hyperprolactinemia as a causal factor of sexual dysfunction is well established (Gillam et al. 2006). Nevertheless, a putative feedback of PRL to dopaminergic populations in humans, as mentioned above, deserves further investigation. So far, the PRL-induced changes in DA turnover for these regions have been examined by only a small number of studies, and the role of inhibiting or promoting dopaminergic activity does not always seem to be clear (for review, see Kruger et al.
(2002, 2005)). However, PRL-responsive neurons in specific hypothalamic nuclei and the feedback of PRL on TIDA neurons have been characterized more intensively. This also included the medial preoptic area, the PVN, and limbic structures which are all of specific importance for sexual drive and function (Bakowska \& Morrell 1997, Brown et al. 2010).

\section{Implantation}

PRL seems to play an important role in implantation and subsequent placentation in the human endometrium (Jabbour et al. 1998, Jones et al. 1998, Jabbour \& Critchley 2001). Animal models and experimental studies suggest that paracrine PRL signaling plays a role in decidualization and embryo implantation (Garzia et al. 2004). In the human endometrium, PRLR protein can be immunolocalized to the glandular epithelium and a subset of stromal cells from the midto late secretory phase, as well as in early decidua (Jabbour et al. 1998, Jones et al. 1998, Gubbay et al. 2002). PRLR transcripts were also detected from the late secretory phase and first trimester decidua (Jones et al. 1998). Progesterone stimulates the production of PRLR when stromal cells transform into decidual cells (Tseng \& Mazella 1999). PRL is recognized as a crucial signal for the initiation and maintenance of decidualization (Qiu et al. 2002). Lack of endometrial PRL during the implantation window seems to be involved in reproductive failure (Garzia et al. 2004). In the event of pregnancy, local expression and secretion of PRL persist until term (Jabbour \& Critchley 2001). PRL enhances endometrial cell growth at low concentrations and inhibits it at high concentrations (Tseng \& Mazella 1999).

The fact that PRL release may be disturbed in overweight patients (Rasmussen \& Kjolhede 2004) and that these patients have increased difficulties in conceiving (Norman \& Clark 1998) further supports the proposed role of PRL in conception and early pregnancy.

Beside hormonal influences, immune functions play an important role in the initiation of a successful pregnancy. PRL, in addition to its endocrine influence on the immune system, acts as a cytokine released within the immune system regulating lymphogenic responses (Matera 1996, Clevenger et al. 1998). Moreover, it has been shown that stress in early pregnancy is able to diminish the secretion of progesterone and PRL, which in turn may alter the pregnancy protective cytokine and immune cell milieu (Arck et al. 2008, Parker \& Douglas 2010). Immunoreactivity of PRLR in a subset of stromal cells may be evidence of paracrine interaction between decidualized cells or of an immunoregulatory role for PRL (Jones et al. 1998).

PRL also exerts effects on the immune system, potentiating T-cell growth in response to various stimuli (Athreya et al. 1994). These effects are felt to be mediated by PRLR present on lymphocytes (Athreya et al. 1994). 


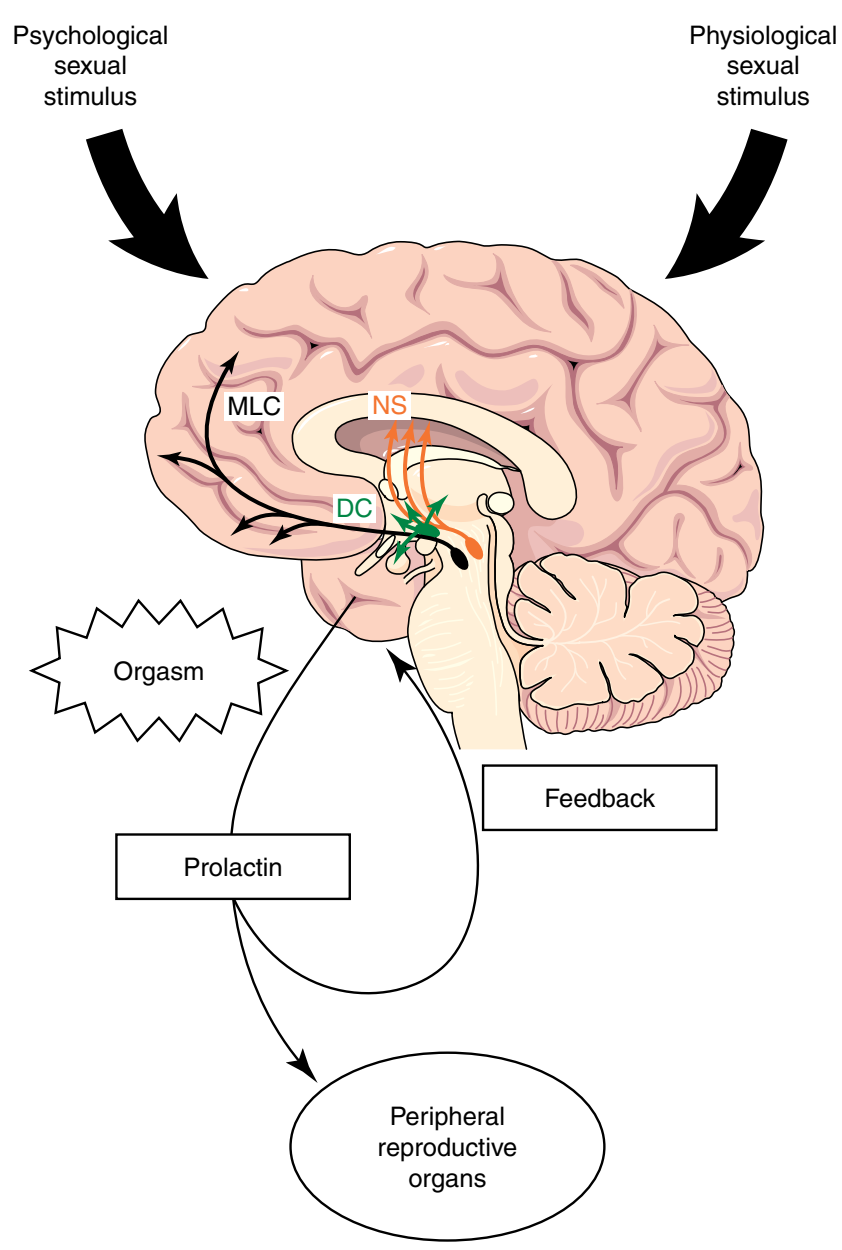

Figure 5 Theoretical model of the impact of PRL secretion following orgasm. PRL may influence peripheral reproductive organs, and/or may feedback to dopaminergic systems in the CNS recognized as playing an important role in the regulation of sexual behavior. DC, diencephalic neurons; MLC, mesolimbocortical neurons; NS, nigrostriatal neurons. Reproduced, with permission, from Kruger TH, Haake P, Hartmann U, Schedlowski M \& Exton MS 2002 Orgasm-induced prolactin secretion: feedback control of sexual drive? Neuroscience and Biobehavioral Reviews 26 31-44. (C) 2002 Elsevier Science Ltd.

Lymphocyte PRL levels vary up to tenfold throughout the menstrual cycle (Athreya et al. 1994). Also, PRLR is expressed in uterine CD56(+) NK cells, and ERK1 and ERK2 of purified uterine CD56(+) NK cells are phosphorylated in response to PRL (Gubbay et al. 2002). Consequently, PRL also seems to exert an effect on immunological mechanisms involved in menstrual cycle, implantation, and early pregnancy.

\section{Pregnancy}

High levels of circulating PRL during human pregnancy are well established, and were described for the first time in the early 1970s (Hwang et al. 1971, Jacobs et al. 1972, L'Hermite \& Robyn 1972). Studies have shown that peak values reach more than five times the normal values at the 20-25th week of gestation (100-250 ng/ml; Boyar et al. 1975, Ben-Jonathan et al. 1996). Nevertheless, investigations on the PRL secretory pattern conducted on pregnant women in their early pregnancy showed that the values were already elevated at gestational week 10 (Boyar et al. 1975). De Hertogh et al. (1975) speculated that PRL concentration may even begin to rise at the third week of gestation. But so far, the precise onset of the PRL increase has not been established.

It is still controversial whether PRL is needed for the successful initialization of pregnancy in humans as it is in rodents. Falk (1992) presented a case in which a woman who had immeasurable serum PRL levels $(<0.1 \mu \mathrm{g} / \mathrm{l})$ and lifelong oligomenorrhea was able to conceive twice after ovulation induction (by clomiphene citrate) and had normal deliveries. In addition, Kauppila et al. (1987) reported that a patient with serum levels of $<2 \mathrm{ng} \mathrm{PRL} / \mathrm{ml}$, severe menstrual cycle irregularities, and puerperal alactogenesis was able to conceive (without ovulation-inducing medication) and has two normal pregnancies. These two cases of normal conception and pregnancies without luteal phase support seem to suggest that not even minimum levels of PRL are necessary for ovulatory function. Nevertheless, there are several facts contradicting this suggestion: Gu (1993) demonstrated that the concentration of serum PRL showed a marked decrease in patients with spontaneous abortion compared to that of women who went to term. Recurrent spontaneous abortion has been associated with abnormal PRL levels (Bussen et al. 1999), and miscarriages are often related to significantly elevated PRL serum values (Hirahara et al. 1998). Furthermore, higher probability of luteal phase disturbances and infertility in women showing reduced postovulatory serum PRL levels (Kauppila et al. 1988) additionally strengthen the concept of PRL involvement in the regulation of the human corpus luteum. The positive outcome in the two case studies mentioned above could be explained by the theory of Schwarzler et al. (1997). They propose that PRL could also be involved in intraovarian regulation, which would (partially) compensate for the absence of endocrine support.

\section{Similarities in and differences between PRL secretion in animal and human reproduction}

When illustrating basic mechanisms of PRL secretion and the possible relevance for reproduction in animals and humans, similarities and differences become evident (Pfaus 1996, Pfaus et al. 2003, Ben-Jonathan et al. 2008). Before drawing the conclusion that the mating- or intercourse-induced PRL surge is important for initialization of early pregnancy in both species, these differences and similarities deserve further attention. 
Regarding PRL production, this is restricted mainly to the pituitary in most animals, whereas in humans, it is also produced by numerous extrapituitary sites where it is regulated by local factors and predominantly acts a cytokine (Ben-Jonathan et al. 1996). This means that even in cases of severe pituitary insufficiency, local PRL production might be enough to maintain specific local functions including reproductive aspects. Consequently, a transfer from animal models to human ones is difficult for this aspect of PRL physiology.

The regulation of PRL release has been extensively studied in rodents and includes a series of releasing and inhibiting factors (for an overview, see for example Ben-Jonathan et al. (2008)). In contrast, the situation in humans seems to be less complex with a prominent role for DA as an inhibiting factor and (to a lesser extent) TRH as a releasing factor (Kruger et al. 2003b). On the reproductive level, we have outlined that PRL is critical in ovarian and other specific reproductive function of both rodents and humans, with a more convincing data basis for the animal models. Secretion patterns throughout the menstrual cycle have a particular pattern in rats with a peak during the afternoon of proestrus, whereas in human females, there is only a slight increase in PRL during the luteal phase. Other endocrine variables such as $\mathrm{LH}$, estradiol, and progesterone show a comparable secretory profile in the two species.

Mating- or sexual intercourse-induced PRL secretion seems to be similar in rodents and humans (Kamel et al. 1975, Kruger et al. 1998, Exton et al. 1999). In addition, in rats, a specific release pattern is switched on after mating with PRL surges during early morning and late afternoon as outlined above (Bertram et al. 2006, Egli et al. 2006). This pattern continues during the first half of pregnancy (10-11 days) before placenta lactogen levels rise. Afterwards, PRL levels again increase on the day before parturition. In contrast, in humans, PRL is chronically elevated during pregnancy from week 6 to 8 of gestation and does not show the kind of rhythmic release pattern seen in rats. However, preliminary data by our own research group might indicate an altered PRL secretion pattern after sexual intercourse with a nocturnal as well as a diurnal PRL surge during a $24 \mathrm{~h}$ analysis comparable to the situation in the rat studies (study in progress). Consequently, there might be some overlap in human and rat physiology during this interval of pregnancy. If this preliminary observation in humans is further validated, consequent studies on the significance of such a PRL secretory pattern will be of interest.

In rodents, the luteotropic activity of PRL involved in the maintenance of corpus luteum makes it a mandatory factor for successful pregnancy (Bachelot \& Binart 2007, Ben-Jonathan et al. 2008). Although in humans, hypo- as well as hyperprolactinemia may cause luteal function deficiency, serum PRL is not so crucial for corpus luteum function and consequently not for pregnancy either.
However, although PRL seems not to be as important for this aspect of reproduction, there is a dramatic increase in PRL during human pregnancy that deserves further research with particular attention on implantation, immune function, fetal growth, and parturition. As mentioned above, local secretion of PRL, which is almost unique to humans, probably has specific functions for steroidogenesis, ovulation, fertilization, implantation, placentation, as well as the prevention of immune rejection of the pregnancy; however, the underlying pathophysiological aspects remain to be elucidated. Finally, the most prominent similarities between the two species seem to lie in lactational regulation by PRL.

\section{Conclusion and outlook}

All these facts together support the hypothesis that the PRL surge induced by sexual activity is important for the successful initialization of animal and, presumably, human pregnancy too - at least to a certain degree. According to the animal studies and mathematical models, we assume that the pronounced PRL surge triggered by sexual contact causes a disturbance in the PRL-DA-oxytocin balance of the hypothalamic and pituitary system that, in turn, leads to a significant change in the PRL secretory pattern.

Combining experimental and mathematical approaches, these kinds of studies may be an initial step in designing and establishing a virtual neuroendocrinological system for humans. A joint clinical and mathematical trial is currently in process, which is designed to verify the core principles of the animal model in humans and to dissect the role of PRL for conception and pregnancy in females.

\section{Declaration of interest}

The authors declare that there is no conflict of interest that could be perceived as prejudicing the impartiality of the research reported.

\section{Funding}

This work was supported by a grant from the Hermann KlausStiftung Zurich (to M Egli, B Leeners, and T H C Kruger). T H C Kruger gratefully acknowledges support from the European Society of Sexual Medicine in terms of the Grant for Medical Research 2008.

\section{References}

Alila HW, Rogo KO \& Gombe S 1987 Effects of prolactin on steroidogenesis by human luteal cells in culture. Fertility and Sterility 47 947-955.

Arbogast LA \& Voogt JL 1996 The responsiveness of tuberoinfundibular dopaminergic neurons to prolactin feedback is diminished between early lactation and midlactation in the rat. Endocrinology 137 47-54. (doi:10. 1210/en.137.1.47) 
Arck PC, Rücke M, Rose M, Szekeres-Bartho J, Douglas AJ, Pritsch M, Blois SM, Pincus MK, Bärenstrauch N, Dudenhausen JW et al. 2008 Early risk factors for miscarriage: a prospective cohort study in pregnant women. Reproductive BioMedicine Online 17 101-113. (doi:10.1016/S1472-6483(10)60300-8)

Arey BJ \& Freeman ME 1989 Hypothalamic factors involved in the endogenous stimulatory rhythm regulating prolactin secretion. Endocrinology 124 878-883. (doi:10.1210/endo-124-2-878)

Arey BJ \& Freeman ME 1992 Activity of oxytocinergic neurons in the paraventricular nucleus mirrors the periodicity of the endogenous stimulatory rhythm regulating prolactin secretion. Endocrinology $\mathbf{1 3 0}$ 126-132. (doi:10.1210/en.130.1.126)

Arey BJ, Averill RL \& Freeman ME 1989 A sex-specific endogenous stimulatory rhythm regulating prolactin secretion. Endocrinology $\mathbf{1 2 4}$ 119-123. (doi:10.1210/endo-124-1-119)

Athreya BA, Zulian F, Godillot AP, Weiner DB \& Williams WV 1994 Prolactin receptor levels on lymphocytes vary with menstrual cycle in women. Pathobiology 62 34-42. (doi:10.1159/000163875)

Bachelot A \& Binart N 2007 Reproductive role of prolactin. Reproduction 133 361-369. (doi:10.1530/REP-06-0299)

Bakowska JC \& Morrell JI 1997 Atlas of the neurons that express mRNA for the long form of the prolactin receptor in the forebrain of the female rat. Journal of Comparative Neurology 386 161-177. (doi:10.1002/ (SICl)1096-9861(19970922)386:2 < 161::AID-CNE1 > 3.0.CO;2-\#)

Ben-Jonathan N \& Hnasko R 2001 Dopamine as a prolactin (PRL) inhibitor. Endocrine Reviews 22 724-763. (doi:10.1210/er.22.6.724)

Ben-Jonathan N, Mershon JL, Allen DL \& Steinmetz RW 1996 Extrapituitary prolactin: distribution, regulation, functions, and clinical aspects. Endocrine Reviews 17 639-669. (doi:10.1210/edrv-17-6-639)

Ben-Jonathan N, LaPensee CR \& LaPensee EW 2008 What can we learn from rodents about prolactin in humans? Endocrine Reviews 29 1-41. (doi:10.1210/er.2007-0017)

Bertram R, Egli M, Toporikova N \& Freeman ME 2006 A mathematical model for the mating-induced prolactin rhythm of female rats. American Journal of Physiology. Endocrinology and Metabolism 290 E573-E582. (doi:10.1152/ajpendo.00428.2005)

Bethea CL \& Neill JD 1979 Prolactin secretion after cervical stimulation of rats maintained in constant dark or constant light. Endocrinology 104 870-876. (doi:10.1210/endo-104-4-870)

Bethea CL \& Neill JD 1980 Lesions of the suprachiasmatic nuclei abolish the cervically stimulated prolactin surges in the rat. Endocrinology 107 1-5. (doi:10.1210/endo-107-1-1)

Boyar RM, Finkelstein JW, Kapen S \& Hellman L 1975 Twenty-four hour prolactin (PRL) secretory patterns during pregnancy. Journal of Clinical Endocrinology and Metabolism 40 1117-1120. (doi:10.1210/ jcem-40-6-1117)

Brody S \& Kruger TH 2006 The post-orgasmic prolactin increase following intercourse is greater than following masturbation and suggests greater satiety. Biological Psychology 71 312-315. (doi:10.1016/j.biopsycho. 2005.06.008)

Brown RS, Kokay IC, Herbison AE \& Grattan DR 2010 Distribution of prolactin-responsive neurons in the mouse forebrain. Journal of Comparative Neurology 518 92-102. (doi:10.1002/cne.22208)

Brumstead J \& Riddick D 1992 Prolactin and the human menstrual cycle. Seminars in Reproductive Endocrinology 10 220-227. (doi:10.1055/ s-2007-1018877)

Bussen S, Sutterlin M \& Steck T 1999 Endocrine abnormalities during the follicular phase in women with recurrent spontaneous abortion. Human Reproduction 14 18-20. (doi:10.1093/humrep/14.1.18)

Clevenger CV, Freier DO \& Kline JB 1998 Prolactin receptor signal transduction in cells of the immune system. Journal of Endocrinology $\mathbf{1 5 7}$ 187-197. (doi:10.1677/joe.0.1570187)

Csapo Al \& Pulkkinen M 1978 Indispensability of the human corpus luteum in the maintenance of early pregnancy. Luteectomy evidence. Obstetrical \& Gynecological Survey 33 69-81. (doi:10.1097/00006254197802000-00001)

De Hertogh R, Thomas K, Bietlot Y, Vanderheyden I \& Ferin J 1975 Plasma levels of unconjugated estrone, estradiol and estriol and of HCS throughout pregnancy in normal women. Journal of Clinical Endocrinology and Metabolism 40 93-101. (doi:10.1210/jcem-40-1-93)
DeMaria JE, Lerant AA \& Freeman ME 1999 Prolactin activates all three populations of hypothalamic neuroendocrine dopaminergic neurons in ovariectomized rats. Brain Research 837 236-241. (doi:10.1016/S00068993(99)01667-4)

Egli M, Bertram R, Sellix MT \& Freeman ME 2004 Rhythmic secretion of prolactin in rats: action of oxytocin coordinated by vasoactive intestinal polypeptide of suprachiasmatic nucleus origin. Endocrinology 145 3386-3394. (doi:10.1210/en.2003-1710)

Egli M, Bertram R, Toporikova N, Sellix MT, Blanco W \& Freeman ME 2006 Prolactin secretory rhythm of mated rats induced by a single injection of oxytocin. American Journal of Physiology. Endocrinology and Metabolism 290 E566-E572. (doi:10.1152/ajpendo.00427.2005)

Erskine MS 1995 Prolactin release after mating and genitosensory stimulation in females. Endocrine Reviews 16 508-528. (doi:10.1210/ edrv-16-4-508)

Exton MS, Bindert A, Kruger T, Scheller F, Hartmann U \& Schedlowski M 1999 Cardiovascular and endocrine alterations after masturbationinduced orgasm in women. Psychosomatic Medicine 61 280-289.

Exton NG, Truong TC, Exton MS, Wingenfeld SA, Leygraf N, Saller B, Hartmann U \& Schedlowski M 2000 Neuroendocrine response to filminduced sexual arousal in men and women. Psychoneuroendocrinology 25 187-199. (doi:10.1016/S0306-4530(99)00049-9)

Exton MS, Kruger TH, Koch M, Paulson E, Knapp W, Hartmann U \& Schedlowski M 2001 Coitus-induced orgasm stimulates prolactin secretion in healthy subjects. Psychoneuroendocrinology 26 287-294. (doi:10.1016/S0306-4530(00)00053-6)

Falk RJ 1992 Isolated prolactin deficiency: a case report. Fertility and Sterility 58 1060-1062.

Freeman ME \& Neill JD 1972 The pattern of prolactin secretion during pseudopregnancy in the rat: a daily nocturnal surge. Endocrinology $\mathbf{9 0}$ 1292-1294. (doi:10.1210/endo-90-5-1292)

Freeman ME, Smith MS, Nazian SJ \& Neill JD 1974 Ovarian and hypothalamic control of the daily surges of prolactin secretion during pseudopregnancy in the rat. Endocrinology 94 875-882. (doi:10.1210/ endo-94-3-875)

Freeman ME, Kanyicska B, Lerant A \& Nagy G 2000 Prolactin: structure, function, and regulation of secretion. Physiological Reviews 80 1523-1631.

Garcea N, Campo S, Siccardi P, Panetta V, Venneri M \& Dargenio R 1983 Effect of drug-induced hyper- and hypoprolactinemia on human corpus luteum. Acta Europaea Fertilitatis 14 35-40.

Garzia E, Borgato S, Cozzi V, Doi P, Bulfamante G, Persani L \& Cetin I 2004 Lack of expression of endometrial prolactin in early implantation failure: a pilot study. Human Reproduction 19 1911-1916. (doi:10.1093/ humrep/deh350)

Gerhold LM, Horvath TL \& Freeman ME 2001 Vasoactive intestinal peptide fibers innervate neuroendocrine dopaminergic neurons. Brain Research 919 48-56. (doi:10.1016/S0006-8993(01)02993-6)

Ghosh R \& Sladek CD 1995 Prolactin modulates oxytocin mRNA during lactation by its action on the hypothalamo-neurohypophyseal axis. Brain Research 672 24-28. (doi:10.1016/0006-8993(94)01340-N)

Gillam MP, Molitch ME, Lombardi G \& Colao A 2006 Advances in the treatment of prolactinomas. Endocrine Reviews 27 485-534. (doi:10. 1210/er.2005-9998)

Grattan DR \& Kokay IC 2008 Prolactin: a pleiotropic neuroendocrine hormone. Journal of Neuroendocrinology 20 752-763. (doi:10.1111/ j.1365-2826.2008.01736.x)

Grosvenor CE, Shyr SW, Goodman GT \& Mena F 1986 Comparison of plasma profiles of oxytocin and prolactin following suckling in the rat. Neuroendocrinology 43 679-685. (doi:10.1159/000124604)

Gu F 1993 Effect of serum prolactin levels on luteal function in patients with recurrent abortions. Zhonghua Fu Chan Ke Za Zhi 28 34-37.

Gubbay O, Critchley HO, Bowen JM, King A \& Jabbour HN 2002 Prolactin induces ERK phosphorylation in epithelial and CD56(+) natural killer cells of the human endometrium. Journal of Clinical Endocrinology and Metabolism 87 2329-2335. (doi:10.1210/jc.87.5.2329)

Gudelsky GA \& Porter JC 1980 Release of dopamine from tuberoinfundibular neurons into pituitary stalk blood after prolactin or haloperidol administration. Endocrinology 106 526-529. (doi:10.1210/endo-106-2-526)

Handschuh K, Guibourdenche J, Tsatsaris V, Guesnon M, Laurendeau I, Evain-Brion D \& Fournier T 2007 Human chorionic gonadotropin 
expression in human trophoblasts from early placenta: comparative study between villous and extravillous trophoblastic cells. Placenta $\mathbf{2 8}$ 175-184. (doi:10.1016/j.placenta.2006.01.019)

Hinney B, Henze C \& Wuttke W 1995 Regulation of luteal function by luteinizing hormone and prolactin at different times of the luteal phase. European Journal of Endocrinology 133 701-717. (doi:10.1530/eje. $0.1330701)$

Hirahara F, Andoh N, Sawai K, Hirabuki T, Uemura T \& Minaguchi H 1998 Hyperprolactinemic recurrent miscarriage and results of randomized bromocriptine treatment trials. Fertility and Sterility $\mathbf{7 0}$ 246-252. (doi:10. 1016/S0015-0282(98)00164-2)

Hiroi M 1988 Direct Actions of Prolactin on the Ovary, Basel: Karger.

Hunter MG 1984 Prolactin stimulates steroidogenesis by human luteal tissue in vitro. Journal of Endocrinology 103 107-110. (doi:10.1677/joe. 0.1030107 )

Hwang P, Guyda H \& Friesen H 1971 A radioimmunoassay for human prolactin. PNAS 68 1902-1906. (doi:10.1073/pnas.68.8.1902)

Jabbour HN \& Critchley HO 2001 Potential roles of decidual prolactin in early pregnancy. Reproduction 121 197-205. (doi:10.1530/rep. 0.1210197)

Jabbour HN, Critchley HO \& Boddy SC 1998 Expression of functional prolactin receptors in nonpregnant human endometrium: janus kinase-2, signal transducer and activator of transcription-1 (STAT1), and STAT5 proteins are phosphorylated after stimulation with prolactin. Journal of Clinical Endocrinology and Metabolism 83 2545-2553. (doi:10.1210/ jc.83.7.2545)

Jacobs LS, Mariz IK \& Daughaday WH 1972 A mixed heterologous radioimmunoassay for human prolactin. Journal of Clinical Endocrinologyand Metabolism 34 484-490. (doi:10.1210/jcem-34-3-484)

Jones RL, Critchley HO, Brooks J, Jabbour HN \& McNeilly AS 1998 Localization and temporal expression of prolactin receptor in human endometrium. Journal of Clinical Endocrinology and Metabolism 83 258-262. (doi:10.1210/jc.83.1.258)

Kacsoh B 2000 Endocrine Physiology. New York: McGraw-Hill.

Kamel F, Mock EJ, Wright WW \& Frankel AI 1975 Alterations in plasma concentrations of testosterone, $\mathrm{LH}$, and prolactin associated with mating in the male rat. Hormones and Behavior 6 277-288. (doi:10.1016/0018506X(75)90014-8)

Katabuchi H \& Ohba T 2008 Human chorionic villous macrophages as a fetal biological shield from maternal chorionic gonadotropin. Development, Growth \& Differentiation 50 299-306. (doi:10.1111/ j.1440-169X.2008.01030.x)

Kauppila A, Chatelain P, Kirkinen P, Kivinen S \& Ruokonen A 1987 Isolated prolactin deficiency in a woman with puerperal alactogenesis. Journal of Clinical Endocrinology and Metabolism 64 309-312. (doi:10.1210/ jcem-64-2-309)

Kauppila A, Martikainen H, Puistola U, Reinila M \& Ronnberg L 1988 Hypoprolactinemia and ovarian function. Fertility and Sterility 49 437-441.

Kawagoe S, Kaneko N \& Hiroi M 1988 Twenty-four Hour Secretory Patterns of Prolactin in Women. Basel: Karger.

Kelly PA, Ali S, Rozakis M, Goujon L, Nagano M, Pellegrini I, Gould D, Djiane J, Edery M, Finidori J et al. 1993 The growth hormone/prolactin receptor family. Recent Progress in Hormone Research 48 123-164.

Khan-Dawood FS 1988 Human corpus luteum: immunocytochemical evidence for presence of prolactin. Cell and Tissue Research 251 233-236. (doi:10.1007/BF00215829)

Kokay IC, Bull PM, Davis RL, Ludwig M \& Grattan DR 2006 Expression of the long form of the prolactin receptor in magnocellular oxytocin neurons is associated with specific prolactin regulation of oxytocin neurons. American Journal of Physiology. Regulatory, Integrative and Comparative Physiology 290 R1216-R1225. (doi:10.1152/ajpregu. 00730.2005)

Kruger T, Exton MS, Pawlak C, von zur Muhlen A, Hartmann U \& Schedlowski M 1998 Neuroendocrine and cardiovascular response to sexual arousal and orgasm in men. Psychoneuroendocrinology 23 401-411. (doi:10.1016/S0306-4530(98)00007-9)

Kruger TH, Haake P, Hartmann U, Schedlowski M \& Exton MS 2002 Orgasm-induced prolactin secretion: feedback control of sexual drive? Neuroscience and Biobehavioral Reviews 26 31-44. (doi:10.1016/ S0149-7634(01)00036-7)
Kruger TH, Haake P, Chereath D, Knapp W, Janssen OE, Exton MS, Schedlowski M \& Hartmann U 2003a Specificity of the neuroendocrine response to orgasm during sexual arousal in men. Journal of Endocrinology 177 57-64. (doi:10.1677/joe.0.1770057)

Kruger TH, Haake P, Haverkamp J, Kramer M, Exton MS, Saller B, Leygraf N, Hartmann U \& Schedlowski M 2003b Effects of acute prolactin manipulation on sexual drive and function in males. Journal of Endocrinology 179 357-365. (doi:10.1677/joe.0.1790357)

Kruger TH, Hartmann U \& Schedlowski M 2005 Prolactinergic and dopaminergic mechanisms underlying sexual arousal and orgasm in humans. World Journal of Urology 23 130-138. (doi:10.1007/s00345004-0496-7)

Lamberts SW \& Macleod RM 1990 Regulation of prolactin secretion at the level of the lactotroph. Physiological Reviews 70 279-318.

Leng G \& Macgregor DJ 2008 Mathematical modelling in neuroendocrinology. Journal of Neuroendocrinology 20 713-718. (doi:10.1111/ j.1365-2826.2008.01722.x)

Lerant AA, DeMaria JE \& Freeman ME 2001 Decreased expression of fosrelated antigens (FRAs) in the hypothalamic dopaminergic neurons after immunoneutralization of endogenous prolactin. Endocrine 16 181-187. (doi:10.1385/ENDO:16:3:181)

Leroy-Martin B, Bouhdiba M, Saint Pol P \& Peyrat JP 1989 Peripheral effects of prolactin in reproductive function. II. Female reproductive function. Journal de Gynécologie, Obstétrique et Biologie de la Reproduction 18 288-294.

L'Hermite M \& Robyn C 1972 Human pituitary prolactin: radioimmunologic detection and level during pregnancy. Annales d'Endocrinologie 33 357-360.

Matera L 1996 Endocrine, paracrine and autocrine actions of prolactin on immune cells. Life Sciences 59 599-614. (doi:10.1016/0024-3205 (96)00225-1)

McNatty KP, Sawers RS \& McNeilly AS 1974 A possible role for prolactin in control of steroid secretion by the human Graafian follicle. Nature $\mathbf{2 5 0}$ 653-655. (doi:10.1038/250653a0)

Niswender GD, Juengel JL, Silva PJ, Rollyson MK \& McIntush EW 2000 Mechanisms controlling the function and life span of the corpus luteum. Physiological Reviews 80 1-29.

Norman RJ \& Clark AM 1998 Obesity and reproductive disorders, a review. Reproduction, Fertility, and Development 10 55-63. (doi:10.1071/ R98010)

Parker VJ \& Douglas AJ 2010 Stress in early pregnancy: maternal neuroendocrine-immune responses and effects. Journal of Reproductive Immunology 85 86-92. (doi:10.1016/j.jri.2009.10.011)

Perks CM, Newcomb PV, Grohmann M, Wright RJ, Mason HD \& Holly JM 2003 Prolactin acts as a potent survival factor against C2-ceramideinduced apoptosis in human granulosa cells. Human Reproduction $\mathbf{1 8}$ 2672-2677. (doi:10.1093/humrep/deg496)

Pfaus JG 1996 Frank A. Beach award. Homologies of animal and human sexual behaviors. Hormones and Behavior 30 187-200. (doi:10.1006/ hbeh.1996.0024)

Pfaus JG, Kippin TE \& Coria-Avila G 2003 What can animal models tell us about human sexual response? Annual Review of Sex Research 14 1-63.

Qiu X, Sun X, Christow A, Stabi B \& Gemzell-Danielsson K 2002 The effect of mifepristone on the expression of insulin-like growth factor binding protein-1, prolactin and progesterone receptor mRNA and protein during the implantation phase in human endometrium. Molecular Human Reproduction 8 998-1004. (doi:10.1093/molehr/8.11.998)

Rasmussen KM \& Kjolhede CL 2004 Prepregnant overweight and obesity diminish the prolactin response to suckling in the first week postpartum. Pediatrics 113 e465-e471. (doi:10.1542/peds.113.5.e465)

Refinetti R, Kaufman CM \& Menaker M 1994 Complete suprachiasmatic lesions eliminate circadian rhythmicity of body temperature and locomotor activity in golden hamsters. Journal of Comparative Physiology A 175 223-232. (doi:10.1007/BF00215118)

Reppert SM \& Weaver DR 2002 Coordination of circadian timing in mammals. Nature 418 935-941. (doi:10.1038/nature00965)

Richardson DW, Goldsmith LT, Pohl CR, Schallenberger E \& Knobil E 1985 The role of prolactin in the regulation of the primate corpus luteum. Journal of Clinical Endocrinology and Metabolism 60 501-504. (doi:10. 1210/jcem-60-3-501)

Schibler U \& Sassone-Corsi P 2002 A web of circadian pacemakers. Cell 111 919-922. (doi:10.1016/S0092-8674(02)01225-4) 
Schulz KD, Geiger W, del Pozo E \& Kunzig HJ 1978 Pattern of sexual steroids, prolactin, and gonadotropic hormones during prolactin inhibition in normally cycling women. American Journal of Obstetrics and Gynecology 132 561-566.

Schwarzler P, Untergasser G, Hermann M, Dirnhofer S, Abendstein B \& Berger P 1997 Prolactin gene expression and prolactin protein in premenopausal and postmenopausal human ovaries. Fertility and Sterility 68 696-701. (doi:10.1016/S0015-0282(97)00320-8)

Smith MS, Freeman ME \& Neill JD 1975 The control of progesterone secretion during the estrous cycle and early pseudopregnancy in the rat: prolactin, gonadotropin and steroid levels associated with rescue of the corpus luteum of pseudopregnancy. Endocrinology 96 219-226. (doi:10. 1210/endo-96-1-219)

Soules MR, Clifton DK, Cohen NL, Bremner WJ \& Steiner RA 1989 Luteal phase deficiency: abnormal gonadotropin and progesterone secretion patterns. Journal of Clinical Endocrinology and Metabolism 69 813-820. (doi:10.1210/jcem-69-4-813)

Soules MR, Bremner WJ, Steiner RA \& Clifton DK 1991 Prolactin secretion and corpus luteum function in women with luteal phase deficiency. Journal of Clinical Endocrinology and Metabolism 72 986-992. (doi:10. 1210/jcem-72-5-986)

Stouffer RL \& Hearn JP 1998 Endocrinology of the Transition from Menstrual Cyclicity to Establishment of Pregnancy in Primates. Totowa, New Jersey: Humana Press.

Suganuma N, Kikkawa F, Narita O \& Tomoda Y 1988 Changes in Serum Prolactin Levels During the Normal Menstrual Cycle. Basel: Karger.

Tan GJ \& Biggs JS 1983 Effects of prolactin on steroid production by human luteal cells in vitro. Journal of Endocrinology 96 499-503. (doi:10.1677/ joe.0.0960499)
Tseng L \& Mazella J 1999 Prolactin and its receptor in human endometrium. Seminars in Reproductive Endocrinology 17 23-27. (doi:10.1055/ s-2007-1016208)

Vekemans M, Delvoye P, L'Hermite M \& Robyn C 1977 Serum prolactin levels during the menstrual cycle. Journal of Clinical Endocrinology and Metabolism 44 989-993. (doi:10.1210/jcem-44-5-989)

Vlahos NP, Bugg EM, Shamblott MJ, Phelps JY, Gearhart JD \& Zacur HA 2001 Prolactin receptor gene expression and immunolocalization of the prolactin receptor in human luteinized granulosa cells. Molecular Human Reproduction 7 1033-1038. (doi:10.1093/ molehr/7.11.1033)

Warren WS, Champney TH \& Cassone VM 1994 The suprachiasmatic nucleus controls the circadian rhythm of heart rate via the sympathetic nervous system. Physiology \& Behavior 55 1091-1099. (doi:10.1016/ 0031-9384(94)90392-1)

Weaver DR 1998 The suprachiasmatic nucleus: a 25-year retrospective. Journal of Biological Rhythms 13 100-112. (doi:10.1177/ 074873098128999952)

White MM \& Samson WK 2006 Closing the link in short-loop prolactin feedback. Trends in Endocrinology and Metabolism 17 217-218. (doi:10. 1016/j.tem.2006.06.005)

Received 18 January 2010

First decision 23 February 2010

Revised manuscript received 5 August 2010

Accepted 13 August 2010 